\title{
Cancer-Related Knowledge and Risk Perception among Secondary School Students in Central Uganda
}

\author{
Ivan Chemos, Stephen Kiwuwa Mpugu \\ Makerere University, Kampala, Uganda \\ Email: chemosivan@yahoo.com, mkiwuwa@yahoo.com
}

How to cite this paper: Chemos, I. and Mpugu, S.K. (2022) Cancer-Related Knowledge and Risk Perception among Secondary School Students in Central Uganda. Open Access Library Journal, 9: e8364. https://doi.org/10.4236/oalib.1108364

Received: February 7, 2022

Accepted: February 15, 2022

Published: February 18, 2022

Copyright (๑) 2022 by author(s) and Open Access Library Inc.

This work is licensed under the Creative Commons Attribution International License (CC BY 4.0).

http://creativecommons.org/licenses/by/4.0/

\begin{abstract}
Introduction: Globally, it was estimated that there were 14.9 million new cases of cancer, 8.2 million deaths, and 196.3 million disability-adjusted life years due to cancer annually. Most of the risk factors for cancer increase rapidly during adolescence and these risk factors can be reduced through school-based interventions. In this research, we explored the level of knowledge, and risk perception among secondary school students concerning cancer. Methods: A cross-sectional study was used in which 500 students from five schools in Kampala, Uganda answered the questionnaires. Structured questionnaires were self-administered to advanced level students who consented to participate in the study. Data were analyzed using Statistical Package for Social Sciences (SPSS). Results: The majority (97.8\%) of the students had heard about cancer, most of them didn't know the symptoms of both prostate and cervical cancer, and the most common cancer cases. Only $22 \%$ answered that cancer is hereditary. $91.2 \%$ knew that cancer can be prevented through a healthy lifestyle. $72 \%$ identified unhealthy eating behavior as a risk factor for cancer. $74.8 \%$ knew that cervical cancer is preventable. $90.2 \%$ knew that evil spirits can't cause cancer. Conclusion: The respondents had good knowledge and positive perception about the different cancers though there were several gaps. Incorporation of cancer knowledge in school curricula and with regular updates depending on the prevailing conditions should be done to improve on these gaps.
\end{abstract}

\section{Subject Areas}

Pathology

\section{Keywords}

Cancer, Knowledge, Risk Perception, Students, Health 


\section{Introduction}

Globally, it was estimated that there were 14.9 million new cases of cancer, 8.2 million deaths, and 196.3 million disability-adjusted life years due to cancer annually. The most common cancer cases among males were prostate cancer with 1.4 million cases, and breast cancer for women with 1.8 million cases [1]. In Africa, 715,000 new cancer cases and 542,000 deaths were recorded. It's expected to double in 20 years because of the aging and growing population [2]. In East Africa, the five most common cancers in both men and women included: cervical cancer (34.5\%), breast cancer (19.3\%), Kaposi's sarcoma (14.9\%), Oesophageal cancer (14.9\%), Prostate cancer (14.5\%) [2]. Generally, the risk factors for cancer are a diet rich in saturated fat, low in fresh fruits and vegetables, physical inactivity, tobacco use, and excessive alcohol consumption [3]. Behaviors such as smoking and involvement in sexual activity increase rapidly in early adolescence beginning at 12 years of age [4]. Most of these lifestyle-related risk factors for non-communicable diseases are contributed to during adolescence [5]. A study among college men and women showed that only $55 \%$ of the students performed breast self-examination annually [6]. Other studies among young men and women showed poor knowledge despite a high level of awareness about testicular cancer [7]. The media provides less and incomplete information about cervical cancer [8]. School-based health promotion interventions are of importance especially in improving physical activity among adolescents [9]. Educating students at the school level can cause a positive impact on the prevention of non-communicable diseases including cancer [10]. Most of the studies that have been done in Africa regarding cancer knowledge and risk perception put more focus on the elderly leaving out the young population. However, some studies in European, Asian, and American countries on adolescent/secondary school students on non-communicable diseases/cancer have been shown [5] [6] [7] [8] [9]. A study done among Asian grade 6 students showed that there are some knowledge gaps regarding the spread of cancer [11]. Another study that was done in London among children and young people showed that though they have enough knowledge about cancer, they do not live a healthy lifestyle [12]. In this study, we explored the level of knowledge, and risk perception among secondary school students concerning cancer. Many health awareness campaigns have been conducted at schools for example in our region but have been heavily skewed to communicable diseases taking Uganda as an example. These health education initiatives have not assessed health behaviors or practices in the context of non-communicable diseases especially cancer. This study was a preliminary survey to assess cancer awareness and perceptions of risk among secondary school students to appropriate health education messages for cancer prevention and control.

\section{Methods}

The study was done in five schools of Kampala, Uganda selected from the minis- 
try of Education and sports. This study was done in 2018-2019. Senior 5 and Senior 6 students above 18 years of age participated in the study. Across-sectional study was used with a sample size of 500 participants. Purposive sampling was used, the sample size estimation was also purposive. The selection criteria were based on gender and whether the schools were day or boarding or single or mixed sex. Schools selected were 1 single-sex girl's boarding school, 2 mixed (boys and girls) boarding schools, and 2 mixed (boys' and girls') day schools. A pre-test was done on 6 students from different schools that were not going to take part in the actual study to standardize the questionnaire. A self-administered questionnaire written in simple English was given, and students were asked to answer individually. The Questionnaire had 3 parts: demographic information, Participants' general knowledge, and risk perception towards cancer. Data were entered and analyzed using SPSS version 20.0. Descriptive statistics were used to calculate demographic variables. Bivariate analysis was used to determine the relationship between demographic information and Knowledge scores, risk perception. Approval for the study was obtained from the Research Ethics Committee School of Biomedical Sciences College of Health Sciences, Makerere University.

\section{Results}

\subsection{Demographic Characteristics}

Overall, 500 students completed the questionnaires, though some questions were left unanswered leading to variability in total responses for the questions assessed. There were slightly more female participants than male participants 293 (58.6\%). The age range was 16 to 27 years with a mean of 18 years, 285 (57\%) were doing science subjects. Only one school was private, one school was a single-sex girl's school; the others were mixed boys and girls. Of the five schools, one was a day school; one was a boarding school, the other 3 were mixed day and boarding schools. The majority of the students practiced Islam 167 (33.3\%) as shown in Table 1.

\subsection{Knowledge}

As illustrated in Table 2, the majority (97.8\%) of the students said they had heard about cancer. When asked about the importance of cancer as a cause of death among the elderly and the youth, $60.2 \%$ stated cancer is a major cause of adult death, whereas $28.2 \%$ indicated that cancer is a major cause of death among the youth. About forty-eight percent of the students stated that cancer is a curable disease, about half of the respondents stated that a man who experiences difficulty in urination could be having prostate cancer, approximately $43.8 \%$ knew that one with abnormal vaginal bleeding as a symptom could be having cervical cancer. They were also asked about how much they thought they knew about the different types of cancer, most known cancer cases were; breast cancer $66.8 \%$, lung cancer 58.3 , skin cancer 45.2 , and cervical cancer 42.8 . The 
Table 1. Demographic characteristics of secondary school students.

\begin{tabular}{|c|c|}
\hline Characteristic & Frequency (\%) \\
\hline \multicolumn{2}{|l|}{ Sex } \\
\hline Male & $207(41.4)$ \\
\hline Female & $293(58.6)$ \\
\hline \multicolumn{2}{|l|}{ Age } \\
\hline $16-20$ & $470(94)$ \\
\hline $21-25$ & $30(6)$ \\
\hline Mean, IQR ${ }^{*}$ & $18,16-27$ \\
\hline \multicolumn{2}{|l|}{ Subject } \\
\hline Arts & $215(43)$ \\
\hline Sciences & $285(57)$ \\
\hline \multicolumn{2}{|l|}{ School type } \\
\hline Public & $400(80)$ \\
\hline Private & $100(20)$ \\
\hline \multicolumn{2}{|l|}{ School gender } \\
\hline Mixed boys and girls & $400(80)$ \\
\hline Single & $100(20)$ \\
\hline \multicolumn{2}{|l|}{ School residency type } \\
\hline Day & $100(20)$ \\
\hline Boarding & $100(20)$ \\
\hline Mixed Day and boarding & $300(60)$ \\
\hline \multicolumn{2}{|l|}{ Religion } \\
\hline Anglican & $140(28)$ \\
\hline Catholic & $111(22.2)$ \\
\hline Muslim & $167(33.4)$ \\
\hline Born Again & $82(16.2)$ \\
\hline
\end{tabular}

${ }^{*}$ Mean, interquartile range.

least known cancer cases were; ovarian cancer 90.7\%, followed by esophageal cancer $90.4 \%$, testicular cancer $89.4 \%$, bladder cancer $88.8 \%$, and Pancreatic cancer $88.4 \%$.

As illustrated in Table 3, Students were asked about their source of information regarding cancer. Most of them (93.8\%) obtained their information from the Television or media. 
Table 2. Cancer knowledge among secondary school students.

\begin{tabular}{|c|c|c|}
\hline Parameter & \multicolumn{2}{|c|}{ Response } \\
\hline Statement & Yes & No \\
\hline Ever heard about cancer & $489(97.8)$ & $11(2.2)$ \\
\hline Cancer is a major cause of adult death & $301(60.2)$ & $199(39.8)$ \\
\hline Cancer is a major cause of young people's death & $141(28.2)$ & $359(71.8)$ \\
\hline Cancer is a curable disease & $229(45.8)$ & $261(52.2)$ \\
\hline \multicolumn{3}{|l|}{$\begin{array}{l}\text { A man who has difficulty in urination } \\
\text { may be having }\end{array}$} \\
\hline Prostate cancer & $257(51.4)$ & $217(43.4)$ \\
\hline $\begin{array}{l}\text { One with vaginal bleeding could be } \\
\text { having cervical cancer }\end{array}$ & $219(43.8)$ & $239(47.8)$ \\
\hline $\begin{array}{l}\text { Someone with cancer can fail to have signs and } \\
\text { symptoms }\end{array}$ & $301(60.2)$ & $185(37)$ \\
\hline \multicolumn{3}{|l|}{ Knowledge of different types of cancer } \\
\hline Type of cancer & \multicolumn{2}{|c|}{$\begin{array}{l}\text { don't know about it } \\
\text { Know about it }\end{array}$} \\
\hline Lung & $203(40.6)$ & $294(58)$ \\
\hline Skin & $273(54.7)$ & $226(45.2)$ \\
\hline Stomach & $410(82)$ & $87(17.4)$ \\
\hline Bladder & $444(88.8)$ & $54(10.8)$ \\
\hline Leukaemia & $290(58)$ & $203(40.6)$ \\
\hline Colon & $437(87.4)$ & $57(11.6)$ \\
\hline Breast & $164(32.8)$ & $334(66.8)$ \\
\hline Uterine & $423(84.6)$ & $71(14.2)$ \\
\hline Cervical & $284(56.8)$ & $214(42.8)$ \\
\hline Ovarian & $452(90.7)$ & $46(9.2)$ \\
\hline Testicular & 447 (89.4) & $45(9)$ \\
\hline Prostate & $389(77.8)$ & $109(21.8)$ \\
\hline Pancreas & $442(88.4)$ & $54(10.4)$ \\
\hline Oesophageal & $452(90.4)$ & $42(8.4)$ \\
\hline
\end{tabular}

Table 3. Source of information among secondary school students.

\begin{tabular}{ccc}
\hline Source of information & Yes & No \\
\hline Television or media & $469(93.8)$ & $31(6.2)$ \\
Teachers & $309(61.8)$ & $143(30.6)$ \\
Parents & $296(59.2)$ & $153(30.6)$ \\
\hline
\end{tabular}


As illustrated in Table 4, there was no direct relationship between knowledge of whether cancer is a major cause of adult or youth death and the category of the subject offered by the students $\mathrm{p}>0.05$. More females knew more about breast cancer compared to males $\mathrm{p}<0.05$. There was no association between knowledge about uterine and prostate cancer with sex $\mathrm{p}>0.05$.

\subsection{Risk Perception}

In response to a question that excessive exposure to sunlight predisposes one to cancer, about sixty percent answered yes (Table 5). 86\% knew that cigarette

Table 4. Relationship between knowledge, attitudes, and source of information with selected demographic variables among secondary school students.

\begin{tabular}{|c|c|c|c|c|}
\hline \multicolumn{2}{|c|}{$\begin{array}{c}\text { Variable } \\
\text { Know-nothing }\end{array}$} & $\begin{array}{c}\text { Know } \\
\text { something }\end{array}$ & $95 \% \mathrm{CI}$ & P-Value \\
\hline \multicolumn{5}{|c|}{ Knowledge about Breast cancer } \\
\hline Male & $100(61)$ & $107(32)$ & & \\
\hline Female & $64(39)$ & $227(68)$ & $2.247-4.891$ & $\mathrm{p}<0.05$ \\
\hline \multicolumn{5}{|c|}{ Knowledge about uterine cancer } \\
\hline Male & $178(42.1)$ & $27(38)$ & & \\
\hline Female & $245(57.9)$ & $44(62)$ & $0.706-1.985$ & 0.521 \\
\hline \multicolumn{5}{|c|}{ Knowledge about prostate cancer } \\
\hline Male & $160(41.1)$ & $46(42.2)$ & & \\
\hline Female & $229(58.9)$ & $63(57.8)$ & $0.622-1.472$ & 0.841 \\
\hline \multicolumn{5}{|c|}{ Cancer is a major cause of adult death } \\
\hline & Yes & No & & \\
\hline Science & $163(54.2)$ & $122(61.3)$ & & \\
\hline Arts & $138(45.8)$ & $77(38.7)$ & $0.518-1.073$ & 0.114 \\
\hline \multicolumn{5}{|c|}{$\begin{array}{l}\text { Cancer is a major cause of young } \\
\text { people's death }\end{array}$} \\
\hline Science & $82(58.2)$ & $203(56.5)$ & & \\
\hline Arts & $59(41.8)$ & $156(43.5)$ & $0.720-1.584$ & 0.743 \\
\hline \multicolumn{5}{|c|}{ Source of information; } \\
\hline \multicolumn{5}{|c|}{ Television/media } \\
\hline $\mathrm{MDB}$ & $371(79.1)$ & $29(93.5)$ & & \\
\hline Boarding & $98(20.9)$ & $2(6.5)$ & $0.061-1.113$ & 0.052 \\
\hline \multicolumn{5}{|c|}{ Source of information; Teachers } \\
\hline $\mathrm{MDB}$ & $251(81.2)$ & $107(74.8)$ & & \\
\hline Boarding & $58(18.8)$ & $36(25.2)$ & $0.907-2.338$ & 0.119 \\
\hline \multicolumn{5}{|c|}{ Source of information; Parents } \\
\hline MDB & $231(98)$ & $121(79.1)$ & & \\
\hline Boarding & $65(22)$ & $32(20.9)$ & $0.583-1.514$ & 0.799 \\
\hline
\end{tabular}

MDB-Mixed day and boarding; CI-Confidence interval. 
Table 5. Showing the risk perception among Advanced level secondary school students.

\begin{tabular}{lcc}
\hline \multicolumn{1}{c}{ Statement } & \multicolumn{2}{c}{ Response } \\
\cline { 2 - 3 } & Yes & No \\
\hline $\begin{array}{l}\text { Excessive exposure to sunlight predispose } \\
\text { one to cancer }\end{array}$ & $299(59.8)$ & $181(36.2)$ \\
Smoking a few sticks of cigarettes pose a cancer risk & $430(86)$ & $64(12.8)$ \\
Cancer is a preventable disease & $421(84.2)$ & $72(14.4)$ \\
Cancer is a fatal disease & $355(71)$ & $114(22.8)$ \\
Cancer is a hereditary disease & $110(22)$ & $377(75.4)$ \\
Cancer can be spread from one person to another & $55(11)$ & $437(87.4)$ \\
I can move closer or play with a cancer patient & $434(86.8)$ & $59(11.8)$ \\
Cancer be prevented through a healthy Lifestyle & $456(91.2)$ & $37(7.4)$ \\
Unhealthy eating predispose one to cancer & $360(72)$ & $124(24.8)$ \\
Cervical cancer is preventable & $374(74.8)$ & $92(82.4)$ \\
Cancer caused by evil spirits & $39(7.8)$ & $451(90.2)$ \\
Unsafe sexual behaviors predispose one to cancer & $260(52)$ & $214(42.8)$ \\
\hline
\end{tabular}

smoking predisposes to cancer. Only $22 \%$ answered that cancer is hereditary. The majority, $87.4 \%$ knew that cancer is not contagious. $91.2 \%$ knew that cancer can be prevented through a healthy lifestyle. $72 \%$ identified unhealthy eating behavior as a risk factor for cancer. $74.8 \%$ knew that cervical cancer is preventable. Mistakenly, 90.2\% knew that evil spirits can't cause cancer.

As shown in Table 6; there was no relationship between knowing that one with difficulty in urination might be having prostate cancer and whether one is male or female $p>0.05$. There was no relationship between knowing that one with vaginal bleeding might be having cervical cancer and the sex category $\mathrm{p}>$ 0.05 . More respondents from mixed boys' and girls' schools knew that cancer is both hereditary and fatal $\mathrm{p}<0.05$.

\section{Discussion}

In this study, most students had good knowledge about cancer though some students had little information on the common cancer conditions, yet they had more knowledge of cancer cases which are not even more prevalent in Africa. For example, students knew more about skin cancer as compared to cervical cancer which is considered the most prevalent in Uganda and East Africa. This could be because schools do not have cancer knowledge as part of their curricula, and they get information regarding cancer that is not specific for their locality. Most students in this study (97.8\%) had heard of cancer which concurs with a study that was done among grade 6 students in Jordan which showed $97.1 \%$ to have heard of cancer [11], another that was done among secondary school students in Kaduna, Nigeria revealed that only $2.7 \%$ had never heard of cancer [13]. 
Table 6. Showing the relationship between risk perception and some selected variables among advanced level secondary school students.

\begin{tabular}{|c|c|c|c|c|}
\hline \multirow{2}{*}{ Variable } & \multicolumn{2}{|c|}{ Risk perception } & \multirow{2}{*}{$95 \% \mathrm{CI}$} & \multirow{2}{*}{ P Vale } \\
\hline & Yes & No & & \\
\hline \multicolumn{5}{|c|}{ Cancer is a fatal disease } \\
\hline MBG & $269(75.8)$ & $102(89.5)$ & & \\
\hline SSG & $86(24.2)$ & $12(10.5)$ & $0.193-0.702$ & 0.002 \\
\hline \multicolumn{5}{|c|}{ Cancer is a hereditary disease } \\
\hline MBG & $75(68.2)$ & $313(83)$ & & \\
\hline SSG & $35(31.8)$ & $64(17)$ & $0.270-0.710$ & 0.001 \\
\hline \multicolumn{5}{|c|}{ One with difficulty in urination might be having prostate cancer } \\
\hline Male & $98(38.1)$ & $99(45.6)$ & & \\
\hline Female & $159(61.9)$ & $118(54.4)$ & $0.509-1.060$ & 0.099 \\
\hline \multicolumn{5}{|c|}{ One with vaginal bleeding might be having cervical cancer } \\
\hline Male & $91(41.6)$ & $95(39.7)$ & & \\
\hline Female & $128(58.4)$ & $144(60.3)$ & $0.742-1.565$ & 0.695 \\
\hline
\end{tabular}

MGB-mixed boys' and girls'; SSG-Single sex girls' school; CI-Confidence interval.

The commonest cancers found to be known were breast cancer $66.8 \%$, lung cancer 58.3, skin cancer 45.2 , and cervical cancer 42.8 . This had a similar pattern with the percentage of secondary schools' students who knew someone with a type of cancer in a study that was done in Nigeria, Breast cancer $59.5 \%$, lung cancer 18.5, skin cancer 8.3 and leukemia 4.9\% [13], in other studies, Breast and lung cancer were the most commonly known cancers among the young people [14]. Surprisingly, cervical cancer and prostate cancer which are among the leading causes of morbidity and mortality [2] were not the most known cancers cancer cases. In East Africa, cervical cancer 34.5\%, Breast cancer 19.3\%, Kaposi's sarcoma $14.9 \%$, and prostate cancer $14.5 \%$ [2] are the most common cancers. The least known cancer cases were: ovarian cancer $90.7 \%$, esophageal cancer $90.4 \%$, Testicular cancer $89.4 \%$, Bladder cancer $88.8 \%$, and pancreatic cancer $88.4 \%$. A similar study though was done on a younger population in Asia found that young people were least likely to know about cancer of the reproductive organs, cancer of the esophagus was the least known [14]. Most female correspondents knew about breast cancer more than their male counterparts $\mathrm{p}<0.05$. This could be explained by the fact that breast cancer is more common among females compared to males. The most common source of information was found to be Television/media $93.8 \%$, teachers 61.8 , and parents 59.2 . This corresponds with a similar study in which mass media contributes more than the knowledge from teachers and parents [13]. This contrasts with a study that was done in Germany where parents were the most common sources of information, followed by media, school instructions, and health education outreach campaigns [11]. It is increasingly being observed that televisions/media is becoming one of 
the most common sources of information and therefore this is where most students get cancer information. This study provides evidence of knowledge gaps about cancer awareness among secondary schools in Uganda and these gaps can only be bridged by the incorporation of cancer knowledge in the school curricula. The majority $(86 \%)$ of the students knew that smoking a few sticks of cigarettes poses a risk to cancer. Similar studies showed that $97.4 \%$ of the $6^{\text {th }}$ year, $96.9 \%$ of the $5^{\text {th }}$ year, and $88.2 \%$ of $4^{\text {th }}$ knew that smoking is a risk factor for cancer [10], which is far much higher than the level of knowledge for this study. Another study among children stated that smoking and sunburn are the most common risk factors for cancer [14]. 84.2\% of the respondents knew that cancer is a preventable disease. A study that was done in Gainesville USA among college men and women revealed that having a higher self-efficacy to prevent cancers means there is a higher chance to engage in cancer prevention behaviors [15] although some studies have proven that physical activity declines during adolescence [16].

About $87 \%$ of the respondents knew that cancer cannot be spread from one person to another which is much higher than a similar study where $63.8 \%$ knew that it cannot be spread from one person to another and only $11.8 \%$ would not move closer to a cancer patient which is far much lower than in the same study where $42 \%$ would not move play with a cancer patient [11]. The majority, 91.2\% knew that an unhealthy lifestyle predisposes one to cancer and $72 \%$ knew unhealthy eating is a risk factor for cancer. A similar that was done in Jordan showed that $44 \%$ of the females and $36 \%$ of the males knew that healthy eating is good [17], however, other studies showed that students eat fewer fruits and vegetables with milk or milk products [18]. A study where lifestyle scores for nursing students in pre-and post-training were established showed an increase in lifestyle scores in post-training [19]. This calls for school-based training to improve the risk perception of students towards cancer. $52 \%$ of the students identified unsafe sexual behaviors as a risk factor for cancer. Only $7.8 \%$ of the students thought that cancer is caused by evil spirits unlike other studies where over 33\% think that it's caused by evil spirits [9].

\section{Limitations}

- Some schools didn't comply to participate in the study making the selection process tedious.

- Financial constraints, a grant of 3000 USD was limited to carry out the whole study.

- A lot of time was taken in the process of approval by the Research and Ethics committee.

- Since the study was purposive, findings are not generalizable to the study population.

\section{Conclusions}

The respondents had good knowledge and positive perception about the differ- 
ent cancer types though there were several gaps. Students did not know more about the common cancers and yet they knew more about the rare cancer cases. Incorporation of cancer knowledge in school curricula and training with regular updates depending on the prevailing conditions should be done. This will reduce the knowledge gaps and bring about a positive perception which is key to prevention, early detection, and screening of cancer. Concerned bodies including the Ministry of Education and Sports together with the Ministry of Health should therefore act to reduce the morbidity and mortality related to cancer.

\subsection{What Is Already Known on This Topic?}

- Behaviors such as smoking and involvement in sexual activity increase rapidly in early adolescence beginning at 12 years of age.

- School-based health promotion interventions are of importance especially in improving physical activity among adolescents.

\subsection{What This Study Adds?}

- Most young people know more about the less common cancer cases than the most common cases in the region.

- Several gaps still exist as far as knowledge and risk perception are concerned.

\section{Acknowledgements}

I would like to thank the funding agency Mt. Kenya Foundation, Makerere University, Research assistants; Henry Ssekyanzi, Anthony Kapsawani, Ogwal Daniel and the research participants. Special thanks to my wife Abigail Chepkwurui Chemos for the moral and spiritual support.

\section{Authors' Contributions}

IC contributed to the study development, study design, data collection, and drafting of the paper for publication. SKM contributed to study design, data analysis, and technical support when needed.

\section{Competing Interests}

There are no competing interests.

\section{References}

[1] Global Burden of Disease Cancer Collaboration (2015) Global Burden of Disease Cancer Collaboration (2015) The Global Burden of Cancer 2013. JAMA oncology, 1, 505-527. https://doi.org/10.1001/jamaoncol.2015.0735

[2] Jemal, A., Bray, F., Forman, D., O’Brien, M., Ferlay, J., Center, M. and Parkin, D.M. (2012) Cancer Burden in Africa and Opportunities for Prevention. Cancer, 118, 4372-4384. https://doi.org/10.1002/cncr.27410

[3] National Cancer Institute, US National Institutes of Health (2007) What You Need to Know about Cancer-An Overview. https://www.cancer.gov/about-cancer

[4] Finer L.B. (2007) Trends in Premarital Sex in the United States, 1954-2003. Public 
Health Reports, 122, 73-78. https://doi.org/10.1177/003335490712200110

[5] Perera, B., Ostbye, T., Fernando, N., Abeygunawardena, V., Ariyananda, P.L. and Woods, C. (2007) Health and Health Behavior among Late Adolescents in Southern Sri Lanka. Galle Medical Journal, 12, 13-17. http://doi.org/10.4038/gmj.v12i1.1079

[6] Kratzke, C., Vilchis, H. and Amatya, A. (2013) Breast Cancer Prevention Knowledge, Attitudes, and Behaviors among College Women and Mother-Daughter Communication. J Community Health, 38, 560-568.

https://doi.org/10.1007/s10900-013-9651-7

[7] Rovito, M.J., Gordon, T.F., Bass, S.B. and DuCette, J. (2011) Perceptions of Testicular Cancer and Testicular Self-Examination among College Men: A Report on Intention, Vulnerability, and Promotional Material Preferences. American Journal of Men's Health, 5, 500-507. https://doi.org/10.1177/1557988311409023

[8] Casciotti, D.M., Smith, K.C., Andon, L., Vernick, J., Tsui, A. and Klassen, A.C. (2014) Print News Coverage of School-Based Human Papillomavirus Vaccine Mandates. Journal of School Health, 84, 71-81. https://doi.org/10.1111/josh.12126

[9] Vander Ploeg, K.A., Maximova, K., McGavock, J., Davis, W. and Veugelers, P. (2014) Do School-Based Physical Activity Interventions Increase or Reduce Inequalities in Health? Social Science \& Medicine, 112, 80-87. https://doi.org/10.1016/j.socscimed.2014.04.032

[10] Bartlett, E.E. (1981) The Contribution of School Health Education to Community Health Promotion: What Can We Reasonably Expect? American Journal of Public Health, 71, 1384-1391. https://doi.org/10.2105/AJPH.71.12.1384

[11] Shihab, R.A., Obeidat, N.A., Bader, R.K., Shtaiwi, A., Ayub, A. and Hawari, F.I. (2012) Cancer-Related Knowledge, Attitudes, and Risk Perception among 6 Grade students in Jordan. Studies in Health Technology and Informatics, 172, 155-160.

[12] Oakley, A., Bendelow, G., Barnes, J., Buchanan, M. and Nasseem Husain, O.A. (1995) Health and Cancer Prevention: Knowledge and Beliefs of Children and Young People. BMJ, 310, 1029-1033. https://doi.org/10.1136/bmj.310.6986.1029

[13] Sule, S.T., Shehu, S.M. and Ukwenya, J.E. (2014) Risk Factors for Common Cancers in Nigeria: Knowledge, Attitudes and Practice among Secondary School Students in Kaduna, Nigeria. International Journal of Medicine and Medical Sciences, 6, 34-41. https://doi.org/10.5897/IJMMS2013.0970

[14] Knighting, K., Rowa-Dewar, N., Malcolm, C., Kearney, N. and Gibson, F. (2011) Children's Understanding of Cancer and Views on Health-Related Behaviour: A 'Draw And Write' Study. Child Care Health and Development, 37, 289-299. https://doi.org/10.1111/j.1365-2214.2010.01138.x

[15] Werk, R.S., Hill, J.C. and Graber, J.A. (2017) Impact of Knowledge, Self-Efficacy, and Perceived Importance on Steps Taken Toward Cancer Prevention among College Men and Women. Journal of Cancer Education, 32, 148-154. https://doi.org/10.1007/s13187-016-0996-3

[16] Allison, K.R., Adlaf, E.M., Dwyer, J.J., Lysy, D.C. and Irving, H.M. (2007) The Decline in Physical Activity among Adolescent Students: A Cross-National Comparison. Canadian Journal of Public Health/Revue Canadienne de Sante' e Publique, 98, 97-100. https://doi.org/10.1007/BF03404317

[17] Al-Sheyab, N.A., Alomari, M.A., Hayajneh, A.A. and Shah, S. (2019) Attitudes and Perceived Barriers toward Healthy Lifestyle Behaviors in Jordanian Adolescents: A Developing Country Perspective. Adolescent Health, Medicine and Therapeutics, 10, 39-47. https://doi.org/10.2147/AHMT.S181001 
[18] Al-Sagarat, A.Y. and Al Kalaldeh, M.T. (2017) Prevalence of Health-Risk Behaviors among Government Schools' Students in Jordan. Iranian Journal of Public Health, 46, $1669-1678$.

[19] Bektas, M., Malak, A.T., Yumer, A.S., Korkmaz, M. and Özkan, A. (2010) Turkish University Students' Nutritional Habits Regarding Cancer Prevention and Healthy Lifestyles. Asian Pacific Journal of Cancer Prevention, 11, 1347-1350. 


\section{QUESTIONNAIRE}

\section{Demographics}

1) Sex (tick)

Male $\square \quad$ Female $\square$

2) Age.............State your last birthday.

3) Class (specify science or arts)

4) The school (tick)

Private $\square \quad$ Public $\square$

5) School gender

Mixed $\square \quad$ Girls only $\square \quad$ Boys only

6) School residency type

Day $\square \quad$ Boarding $\square \quad$ Mixed day and boarding $\square$

7) Religion

Anglican $\square$ Catholic $\square \quad$ Muslim $\square$

Born again (Pentecostal) $\square$

Cancer knowledge, answer, YES, NO (circle the most appropriate answer)

1) Have you ever heard about cancer?
(a) YES
(b) NO
2) Cancer is a major cause of adult death

(a) YES

(b) NO

3) Cancer is a major cause of young people's death?
(a) YES
(b) NO

What are the sources of information you have received about cancer (questions $2-4)$ ?

2) Television or media
(a) YES
(b) NO
3) Teachers
(a) YES
(b) NO
4) Parents
(a) YES
(b) NO
5) Is cancer a curable disease?
(a) YES
(b) NO

6) Is it true that a man who finds difficulty in urinating may be having prostate cancer?

(a) YES 
(b) NO

7) Is it true that someone who has vaginal bleeding could be having cervical cancer?
(a) YES
(b) NO
8) Is it true that someone with cancer can fail to have signs and symptoms?
(a) YES
(b) NO

\section{Awareness of different types of cancer}

9) Lung cancer
(a) Never heard of it
(b) Heard of it, don't know more about it
(c) Heard of it, know something about it

10) Skin cancer

(a) Never heard of it

(b) Heard of it, don't know more about it

(c) Heard of it, know something about it

11) Stomach cancer

(a) Never heard of it

(b) Heard of it, don't know more about it

(c) Heard of it, know something about it

12) Bladder cancer

(a) Never heard of it

(b) Heard of it, don't know more about it

(c) Heard of it, know something about it

13) Leukemia

(a) Never heard of it

(b) Heard of it, don't know more about it

(c) Heard of it, know something about it

14) Colon cancer

(a) Never heard of it

(b) Heard of it, don't know more about it

(c) Heard of it, know something about it

15) Breast cancer

(a) Never heard of it

(b) Heard of it, don't know more about it

(c) Heard of it, know something about it

16) Uterine cancer

(a) Never heard of it

(b) Heard of it, don't know more about it

(c) Heard of it, know something about it

17) Cervical cancer

(a) Never heard of it 
(b) Heard of it, don't know more about it

(c) Heard of it, know something about it

18) Ovarian cancer

(a) Never heard of it

(b) Heard of it, don't know more about it

(c) Heard of it, know something about it

19) Testicular cancer

(a) Never heard of it

(b) Heard of it, don't know more about it

(c) Heard of it, know something about it

20) Prostate cancer

(a) Never heard of it

(b) Heard of it, don't know more about it

(c) Heard of it, know something about it

21) Pancreas

(a) Never heard of it

(b) Heard of it, don't know more about it

(c) Heard of it, know something about it

22) Esophageal cancer

(a) Never heard of it

(b) Heard of it, don't know more about it

(c) Heard of it, know something about it

\section{RISK PERCEPTION}

1) Can excessive exposure to sunlight predispose one to cancer?
(a) YES
(b) $\mathrm{NO}$
2) Does smoking a few cigarettes a week pose a cancer risk?

(a) YES

(b) $\mathrm{NO}$

3) Is cancer a preventable disease?
(a) YES
(b) $\mathrm{NO}$
4) Is cancer a fatal disease?

(a) YES

(b) $\mathrm{NO}$

5) Is cancer a hereditary disease?
(a) YES
(b) $\mathrm{NO}$
6) Can cancer be spread from one person to another?

(a) YES

(b) $\mathrm{NO}$

7) Would you move closer to or play with a cancer patient?

(a) YES 
(b) $\mathrm{NO}$

8) Can cancer be prevented through a healthy lifestyle?

(a) YES

(b) $\mathrm{NO}$

9) Can unhealthy eating predispose one to cancer?

(a) YES

(b) $\mathrm{NO}$

10) Is cervical cancer preventable?

(a) YES

(b) $\mathrm{NO}$

11) Is cancer caused by evil spirits?

(a) YES

(b) $\mathrm{NO}$

12) Can unsafe sexual behaviors predispose one to cancer?

(a) YES

(b) $\mathrm{NO}$

13) In what ways can cancer be prevented?

END 